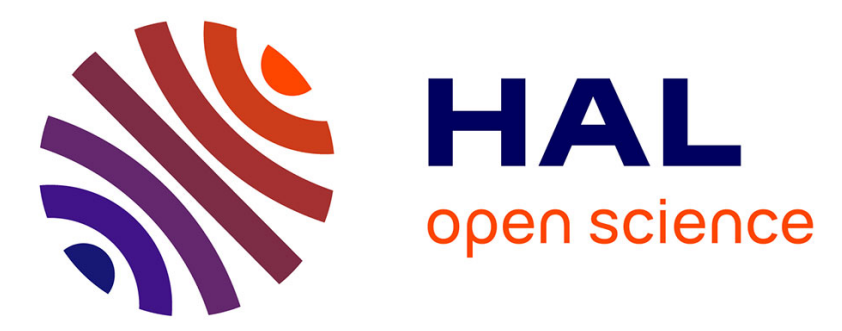

\title{
Epitaxial Growth of Sputtered Ultra-thin NbN Layers and Junctions on Sapphire
}

\author{
J.-C. Villegier, S. Bouat, P. Cavalier, R. Setzu, R. Espiau de Lamaestre, \\ Corentin Jorel, Philippe Odier, Bruno Guillet, Laurence Méchin, Marie-Pierre \\ Chauvat, et al.
}

\section{To cite this version:}

J.-C. Villegier, S. Bouat, P. Cavalier, R. Setzu, R. Espiau de Lamaestre, et al.. Epitaxial Growth of Sputtered Ultra-thin NbN Layers and Junctions on Sapphire. IEEE Transactions on Applied Superconductivity, 2009, 19 (3), pp.3375-3378. 10.1109/TASC.2009.2019243 . hal-00974758

\section{HAL Id: hal-00974758 https://hal.science/hal-00974758}

Submitted on 7 Apr 2014

HAL is a multi-disciplinary open access archive for the deposit and dissemination of scientific research documents, whether they are published or not. The documents may come from teaching and research institutions in France or abroad, or from public or private research centers.
L'archive ouverte pluridisciplinaire HAL, est destinée au dépôt et à la diffusion de documents scientifiques de niveau recherche, publiés ou non, émanant des établissements d'enseignement et de recherche français ou étrangers, des laboratoires publics ou privés. 


\title{
Epitaxial Growth of Sputtered Ultra-Thin NbN Layers and Junctions on Sapphire
}

\author{
Jean-Claude Villegier, S. Bouat, P. Cavalier, R. Setzu, R. Espiau de Lamaëstre, C. Jorel, P. Odier, B. Guillet,
} L. Mechin, M. P. Chauvat, and P. Ruterana

\begin{abstract}
High crystalline quality of ultra-thin $\mathrm{NbN}$ layers and of $\mathrm{NbN}-\mathrm{MgO}-\mathrm{NbN}$ tri-layers, epitaxially grown by DC-magnetron sputtering in the superconducting B1-cubic phase has been achieved in a reproducible way on three different orientations of sapphire substrates i.e. R-, A- and M-planes. Significant improvements such as higher $\mathrm{Tc}$, higher $\mathrm{Jc}$ and lower resistivity have been obtained by growing untwined (110) oriented $\mathrm{NbN}$ layers on M-plane orientation of sapphire. Uniform, low roughness, 3-5 $\mathrm{nm}$ thick films with Tc above $12 \mathrm{~K}$ and Jc above $5 \mathrm{MA} / \mathrm{cm}^{2}$ at $4.2 \mathrm{~K}$ were obtained. Characterizations by TEM, AFM and $\mathrm{X}$-Ray diffraction evidence that growth of untwined NbN on M-plane lead to a better epitaxy in comparison with twinned films observed on other sapphire orientations. We observe that the reduction of the substrate temperature from $600^{\circ} \mathrm{C}$ to $300^{\circ} \mathrm{C}$ during the deposition of $\mathrm{NbN}$ or $\mathrm{NbN}-\mathrm{MgO}-\mathrm{NbN}$ layers thicker than $20 \mathrm{~nm}$ prevents the nucleation of the competing HCP NbN phase. Moreover, $1.5 \mathrm{~nm}$ thick AlN or MgO over-layers sputtered in-situ prevent ultra-thin $\mathrm{NbN}$ films degradation through aging. The formation of $\mathrm{Nb}_{2} \mathrm{~N}_{\mathrm{y}} \mathrm{O}_{5-\mathrm{x}}(\sim 2.2 \mathrm{~nm})$ at the unprotected $\mathrm{NbN}$ surface and of interfacial $\mathrm{NbO}(\sim 0.7 \mathrm{~nm})$ native oxides has been observed by XPS. It is forecasted that such improvements in ultra-thin $\mathrm{NbN}$ films deposited uniformly on 3 and 4 inch sapphire wafers is a key in the future development of superconducting single photon detectors, THz HEB mixers and also in low noise quantum analogical and digital Josephson devices.
\end{abstract}

Index Terms-Josephson epitaxial junctions, niobium nitride compounds, superconducting epitaxial layers, superconducting filaments and wires, thin films.

\section{INTRODUCTION}

$\mathbf{H}$ IGH structural quality and high reliability in the single crystal deposition of ultra-thin films ( 3 to $20 \mathrm{~nm}$ thick) of the superconducting B1-cubic phase of niobium nitride $(\mathrm{NbN})$ [1], [2] have been shown to be mandatory for the development of

Manuscript received August 27, 2008. First published June 05, 2009; current version published July 15, 2009. This work was supported in part by the Grant EC Sinphonia NMP4-CT-2005-16433 and the Grant 'HyperSCAN'ANR T-COM-06-023.

J.-C. Villegier, S. Bouat, P. Cavalier, and R. Setzu are with the CEA, Institute of Nanosciences and Cryogenics, SPSMS, CEA-Grenoble, Grenoble 38054, France (e-mail: jean-claude.villegier@cea.fr).

R. Espiau de Lamaëstre is with CEA-Leti-MINATEC, Grenoble 38054 , France.

C. Jorel is with Leti-MINATEC/CNRS-LTM, Grenoble 38054, France.

P. Odier is with the CNRS, Institut Néel, Grenoble 38042, France.

B. Guillet and L. Mechin are with GREYC (UMR 6072), CNRS, ENSICAEN, Université de Caen Basse-Normandie, Caen 14032, France.

M. P. Chauvat and P. Ruterana are with CIMAP (UMR 6252), CNRS, CEA, ENSICAEN, Caen 14050, France.

Color versions of one or more of the figures in this paper are available online at http://ieeexplore.ieee.org.

Digital Object Identifier 10.1109/TASC.2009.2019243 efficient infrared superconducting nanowire single photon detectors (SNSPD), counters, spectrometers [3]-[5] and of large IF-bandwidth $\mathrm{THz}$ hot electron mixers [6]. Quantum analog and digital integrated circuits performances should also be increased by using better quality $\mathrm{NbN}$ junction tri-layers, with large characteristic voltage $\left(I_{C} R_{N}\right)$ and large operating temperatures. This should be achieved through the improvement of $\mathrm{NbN}$ crystalline quality of junction electrodes and barrier, which is linked to a reduction in London penetration depth value and to an increase in energy gap [7]-[9].

Efforts devoted to the $\mathrm{NbN}$ layer growth aim at improving the critical temperature Tc and the critical current density Jc, but also the long term reliability and the reproducibility of few nanometer thick layers covering uniformly a large area wafer. Long term reliability of very thin layers is an issue, which would make $\mathrm{NbN}$ films attractive among other superconducting metals and compound materials such as $\mathrm{Nb}$ or YBCO, which are more sensitive to oxygen in- and out-diffusion and sensitive to chemical degradations.

The choice of substrate is critical in regards to its crystalline, electronic and physicochemical properties to be matched with the $\mathrm{NbN}$ ones [2]. Among single crystal wafers, Silicon, Sapphire and $\mathrm{MgO}$ substrates are generally considered first. Cubic $\mathrm{MgO}$ substrates give the best match with the $\mathrm{B} 1$ nitride structure leading to an epitaxial relationship that we observed even when the substrate is maintained at room temperature during the $\mathrm{NbN}$ sputter deposition [10]. By characterizing the epitaxial growth and the superconducting transport properties of $\mathrm{NbN}$ nanowires on three different orientations of sapphire we intend to bring new arguments for considering M-plane sapphire as the best compromise for achieving uniform superconducting performances in long nanowires, which is a critical issue in SSPDs [11]. We also take into account that $\mathrm{MgO}$ substrates are expensive and hydrophilic, while it would be difficult in most of the sputtering systems to deposit uniformly a suitable crystalline template on silicon wafers after in-situ removing of the $\mathrm{SiO}_{2}$ surface oxide without damage.

\section{NbN Film Deposition Conditions}

$\mathrm{NbN}$ films were deposited on the R-, A- and M-plane orientations of epitaxially polished ( 3 or 4 inches in diameter) sapphire substrates, from Kyocera. $\mathrm{MgO}$ (100) oriented substrates were also used for some of the comparisons. The $\mathrm{NbN}$ films were grown by reactive DC-magnetron sputtering (Alcatel-650 equipment) done at about $600^{\circ} \mathrm{C}$ substrate temperature, as we described previously [10]. Very thin $\mathrm{NbN}$ layers were obtained in a reproducible way by controlling both the nitrogen-argon reactive plasma sputtering conditions (total pressure $\mathrm{P}_{\text {tot }}=1.8810^{-2}$ mbar; $\sim 10 \% \mathrm{~N}_{2}$ partial pressure; $4 \mathrm{~A}$ as cathode dc current) and the number of turns in the rotation of the 
TABLE I

NbN LAYERS AND OVER-LAYERS STUDIED

\begin{tabular}{lccccc}
\hline \hline & $\begin{array}{c}\text { Sapphire } \\
\text { plane cut }\end{array}$ & Overlayer & $\begin{array}{c}\text { NbN } \\
\text { thickness }\end{array}$ & $\begin{array}{c}\text { Resistivity } \\
(300 \mathrm{~K})\end{array}$ & Tc (K) \\
\hline A & R-plane & $\operatorname{AlN}(1.5 \mathrm{~nm})$ & $5.2 \mathrm{~nm}$ & $138 \mu \Omega . \mathrm{cm}$ & 12.4 \\
B & A-plane & $\mathrm{MgO}(2.2 \mathrm{~nm})$ & $6.8 \mathrm{~nm}$ & $124 \mu \Omega . \mathrm{cm}$ & 13.4 \\
C & M-plane & $\mathrm{AlN}(1.5 \mathrm{~nm})$ & $4.35 \mathrm{~nm}$ & $102 \mu \Omega . \mathrm{cm}$ & 13.3 \\
D & M-plane & $\begin{array}{c}\mathrm{Nb}_{2} \mathrm{O}_{5-\mathrm{x}}(2.2 \mathrm{~nm}) \\
\text { native oxide }\end{array}$ & $2.86 \mathrm{~nm}$ & $142 \mu \Omega . \mathrm{cm}$ & 11.7 \\
\hline \hline
\end{tabular}

substrate holder above the 6 inch diameter $\mathrm{Nb}$ target. In order to prevent their subsequent degradation by oxidation in atmosphere, the $\mathrm{NbN}$ films are generally covered by an in-situ AlN layer $(\sim 1.5 \mathrm{~nm}$ thick) that are RF-sputtered after cooling the wafer to room temperature. Alternative $\mathrm{MgO}$, TaN or bi-layers were also sputtered, for comparison some of the characterized over-layers are presented in Table I.

A significant improvement in the $\mathrm{NbN}$ film quality on M-plane orientation of sapphire versus R-plane or A-plane (i.e. higher critical temperature (Tc), higher current density at $4.2 \mathrm{~K}$ (Jc) and lower resistivity at $300 \mathrm{~K}$ and $20 \mathrm{~K}$ ) has been observed in a first attempt by growing simultaneously $\mathrm{NbN}$ on the three different wafer cuts [12], [13].

New layers including thinner films, over-layers and multilayers have been grown for this study (on separate runs) on the three sapphire cuts, 3 or 4 inch in diameter for characterizing and comparing their typical structural features. Films have been patterned to study their superconducting properties.

\section{Structural Characterization}

\section{A. X-Ray Diffraction and Reflectivity Characterizations}

The microstructure of $\mathrm{NbN}$ films grown on the three sapphire cut substrates has been examined by both symmetric and asymmetric X-ray diffraction using a $\mathrm{Cu} \mathrm{K} \alpha$ source, [Siefert texture apparatus] in the Schulz configuration, indicating pike poles as shown in Fig. 1. The observation of diffraction peaks gives insight on the in-plane and perpendicular orientation of the $\mathrm{NbN}$ film. This confirms that $\mathrm{NbN}$ are both (110) oriented and un-twinned on M-plane, while films are twinned around the (135) orientation on top of R-plane sapphire. Moreover $\mathrm{NbN}$ films are also found to be twinned and (111) oriented on the A-plane sapphire substrates.

The $\mathrm{NbN}$ layer thickness and mean roughness were measured by X-ray reflectivity at low angle, using a Philips X'Pert for the data acquisition and the Paratt fit [16] applied to the experimental data.

Fig. 2 presents good fits obtained for determining the thickness of ultra-thin films of $4.35 \mathrm{~nm}(\mathrm{Tc}=13.3 \mathrm{~K})$ and $2.86 \mathrm{~nm}$ $(\mathrm{Tc}=11.7 \mathrm{~K})$ using the Paratt fit applied to $\mathrm{NbN}$ reflectivity versus tilt angle ( $\sim Q$ vector) at low angles (few degrees).

Thicknesses can be determined with an accuracy of about $+/-5 \%$ even when applied to ultra-thin NbN layers of Fig. 2 covered by either an in-situ deposited over-layer or by the native surface oxide of $\mathrm{NbN}$ as described in Table I.
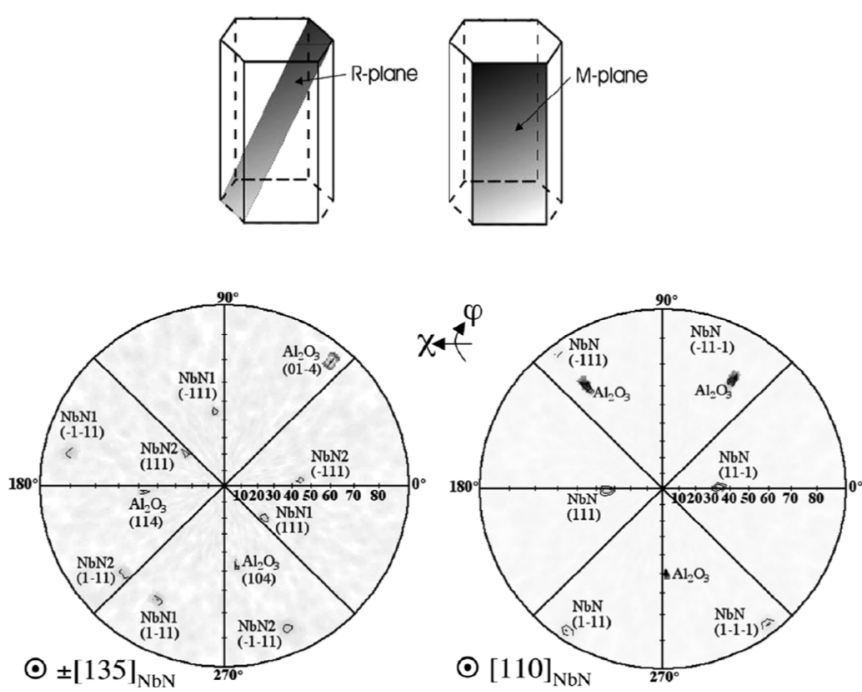

Fig. 1. X-ray pole figures of cubic NbN Bragg reflections on sapphire R-plane and M-plane cuts. Left: on R-plane sapphire $\left(2 \mathrm{q}=35.03^{\circ}\right)$, the two twinning variants are noted $\mathrm{NbN} 1$ and $\mathrm{NbN} 2$. Right: on M-plane sapphire. The contour lines underline the weak $\mathrm{NbN}$ diffraction signal. Diffraction indicates the improved $\mathrm{NbN}$ (110) oriented un-twinned on M-plane.

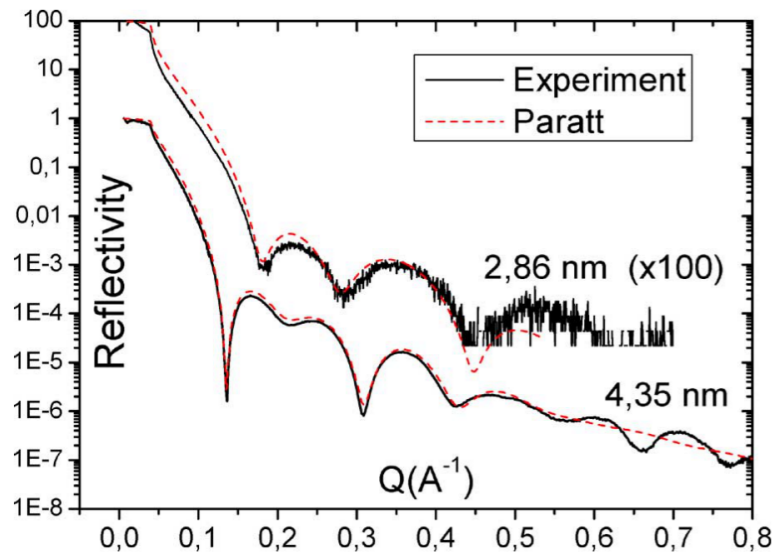

Fig. 2. X-ray reflectivity determination of the thicknesses of two ultra-thin $\mathrm{NbN}$ films as a function of the sample tilt at grazing angles (diffusion vector Q) and fit with the Paratt extraction model [16].

\section{B. HR-TEM Characterization}

High Resolution Transmission Electron Microscopy (HR-TEM) cross-section images of $\mathrm{NbN}$ samples $A, B, C$ in Table I, grown on R-, A- and M-plane sapphire cut substrates fully confirmed the interpretation of the XRD measurements on the $\mathrm{NbN}$ crystalline orientations [12], [13] and on the twinning domains observed, except for growth on M-plane. High resolution microscopy presented in Fig. 3 evidences the good crystalline quality but the different orientations of $\mathrm{NbN}$ observed on M-plane versus R-plane sapphire cuts. There is more insight obtained from TEM and AFM. There are regular surface steps and terraces on R-plane (step distance $\left.\mathrm{d}_{\text {ter }} \sim 11 \mathrm{~nm}\right)$ and on A-plane $\left(\mathrm{d}_{\text {ter }} \sim 7 \mathrm{~nm}\right)$ but M-plane looks flat without any step on it. $\mathrm{NbN}$ strain relaxed grains are found well aligned in-plane on top of the M-plane sapphire, 

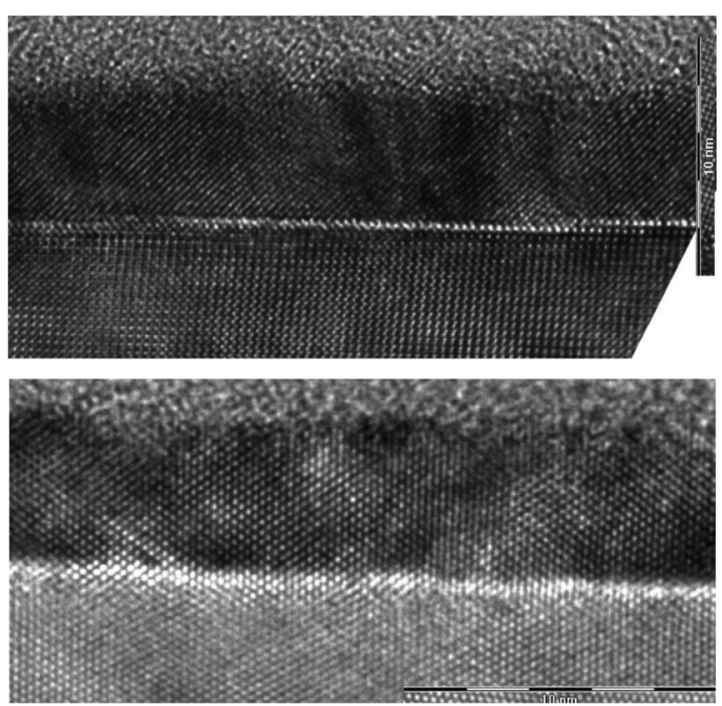

Fig. 3. TEM cross-section observation (rule is $10 \mathrm{~nm}$ ) of (top) sample $A$ in Table I, showing twinned (135) oriented $\mathrm{NbN}$ on R-plane sapphire and (bottom) sample $C$ showing $\mathrm{NbN}$ (110) untwined on M-plane.

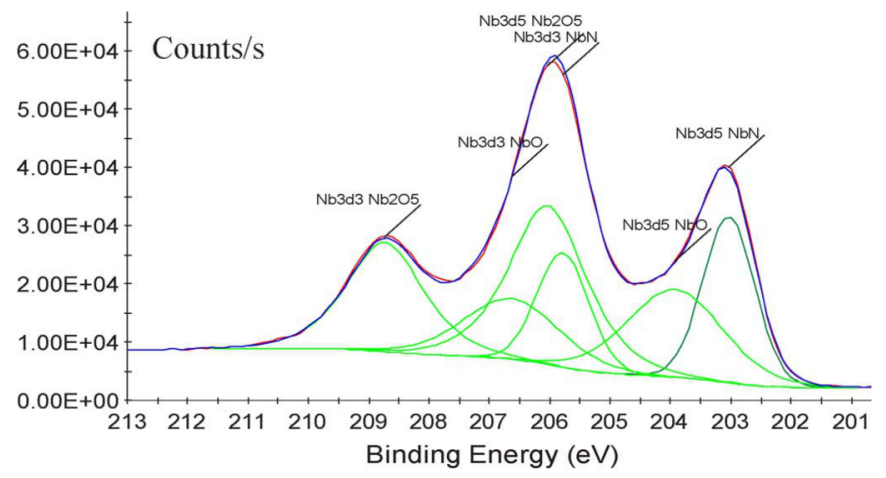

Fig. 4. XPS spectrum of the $\mathrm{Nb}^{3 \mathrm{~d} 3}$ and $\mathrm{Nb}^{3 \mathrm{~d} 5}$ pikes intensity versus binding energy for a $2.9 \mathrm{~nm} \mathrm{NbN}$ covered by its native oxy-nitride (sample D), after de-convolving the presence of $\mathrm{a} \mathrm{Nb}_{2} \mathrm{O}_{5}(1.8 \mathrm{~nm}$ thick) surface compound dominant and of $\mathrm{a} \sim 0.7 \mathrm{~nm} \mathrm{NbO}$ compound at the $\mathrm{NbN}$ interface.

while twinned domains with random sizes on R-and A-plane sapphire are found with some misoriented grains [18].

\section{X-Photoelectron Spectroscopy Characterization}

An ultra-thin $\mathrm{NbN}$ (2.86 nm thick) film grown on M-plane sapphire substrate labeled sample $D$ in Table I, intentionally not covered by any over-layer but by its native oxide grown at room temperature in air, has been analyzed by X-ray Photoelectron Spectroscopy (XPS) and surface scanning at CEAMinatec. The thickness-dependent chemical properties of surface oxy-nitrides are studied for determining the local origin of detrimental $\mathrm{NbN}$ defects acting on the ultra-thin films long term degradation i.e. square resistance increase and Tc decrease. $\mathrm{Nb}^{3 \mathrm{~d} 3}, \mathrm{Nb}^{3 \mathrm{~d} 5}, \mathrm{~N}^{1 \mathrm{~s}}, \mathrm{C}^{1 \mathrm{~s}}$, atom orbit signatures and their energy shift have been studied as described elsewhere [19]. NbN samples A, B, C in Table I, covered by AlN, MgO over-layers have also been studied by XPS in order to understand their better stability under aging.

XPS energy spectrum of the $\mathrm{Nb}^{3 \mathrm{~d} 3}$ and $\mathrm{Nb}^{3 \mathrm{~d} 5}$ from $\mathrm{NbN}$ sample $D$ (2.86 nm thick) covered by its native oxy-nitride after one month storage in air, looks very uniform at a sub-micrometer to $\mathrm{cm}$ scales and is presented in Fig. 4. After pike de-con-

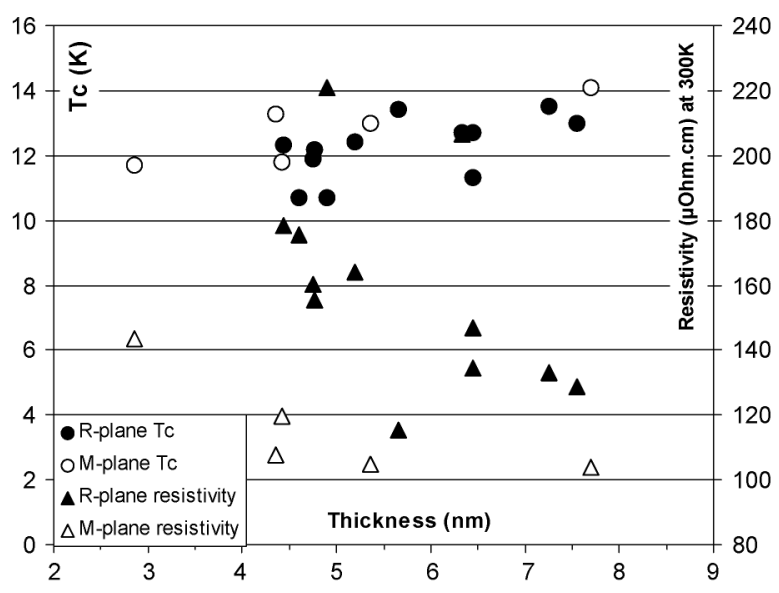

Fig. 5. Measurement of the critical temperature Tc and room temperature resistivity versus $\mathrm{NbN}$ film thickness for films on R-plane and M-plane sapphire substrates.

volving we observed the presence of a dominant $\mathrm{Nb}_{2} \mathrm{O}_{5}(1.8 \mathrm{~nm}$ thick) surface compound and of a $\sim 0.7 \mathrm{~nm}$ thick $\mathrm{NbO}$ compound at the $\mathrm{NbN}$ interface. The total surface oxy-nitride thickness $(\sim 2.5 \mathrm{~nm})$ observed by XPS is found a bit thicker than that taken from the measurement of X-ray reflectivity $(1.8 \mathrm{~nm})$, made only one day after sample deposition. However in the $\mathrm{X}$-ray Paratt fit, interface layer has not been ascribed to a defined compound. We also observed a $10 \%$ increase in $\mathrm{NbN}$ square resistance value between the two measurements. In opposite, we observed that in-situ sputtered $1.5 \mathrm{~nm}$ thick, AlN or $\mathrm{MgO}$ over-layers efficiently prevent from aging effects and formation of $\mathrm{Nb}_{2} \mathrm{~N}_{\mathrm{y}} \mathrm{O}_{5-\mathrm{x}}$ and $\mathrm{NbO}$ native oxy-nitrides [19].

\section{NbN FILMS AND FILAMENTS TRANSPORT PROPERTIES}

The superior transport performances of $\mathrm{NbN}$ layers grown on M-plane sapphire in comparison with the ones grown on R-plane (or on A-plane) measured by the four-point method on un-patterned films are presented in Fig. 5: the critical temperature Tc is increased and the resistivity is decreased when using $\mathrm{M}$-plane versus $\mathrm{R}$-plane sapphire for $\mathrm{NbN}$ thickness in the range of $2.5 \mathrm{~nm}$ to $10 \mathrm{~nm}$.

In Fig. 6 it is evidenced that sharp transitions can be obtained from ultra-thin $\mathrm{NbN}$ layers grown on M-plane sapphire: Tc reaches $13.2 \mathrm{~K}$ uniformly across a 3-inch wafer, for a film thickness of $4.4 \mathrm{~nm}$ (measured by X-ray reflectivity) and $11.7 \mathrm{~K}$ for a $2.9 \mathrm{~nm}$ thick film.

Patterning and processing nanowires have been achieved to confirm that superconducting electronic devices relying on nano-wires would benefit from the more homogeneous properties of $\mathrm{NbN}$ grown on $\mathrm{M}$-plane sapphire without significant process induced degradation.

The $\mathrm{NbN}$ film goes through a four-step low temperature process described elsewhere [17], which includes the deposition and e-beam lithography $\left(\mathrm{U}=100 \mathrm{kV}\right.$, dose $105 \mu \mathrm{C} / \mathrm{cm}^{2}$ ) of a $150 \mathrm{~nm}$ thick NEB22 Sumitomo negative tone resist, followed by reactive ion etching in $\mathrm{SF} 6 / \mathrm{O} 2$ to define the wires.

Resist development was done in a Rohm and Haas MF702 for $45 \mathrm{~s}$ after a post-exposure bake of $90^{\circ} \mathrm{C}$ for $60 \mathrm{~s}$, and then rinsed in water for $180 \mathrm{~s}$. Finally the stripping of the resist was completed using Dupont's EKC-LE solution. The obtained wire widths vary from $50 \mathrm{~nm}$ to $10 \mu \mathrm{m}$, and are $30 \mu \mathrm{m}$ long. Fig. 7 shows that filament conductivity does no more depend 


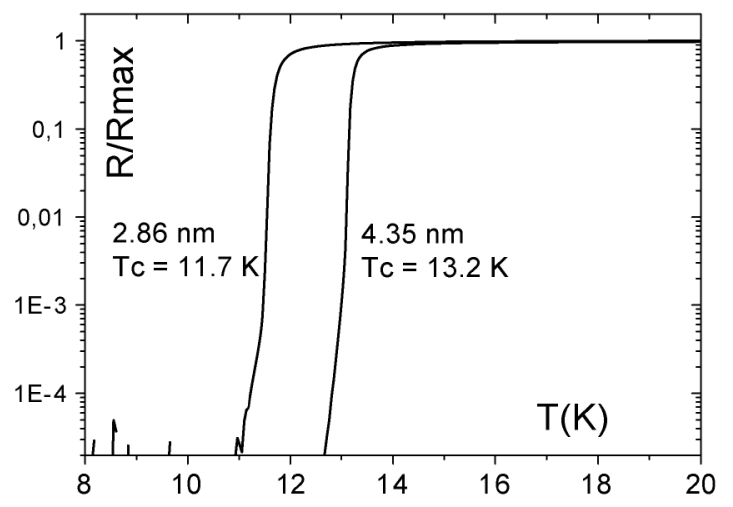

Fig. 6. Critical temperature observed as a function of normalized resistance for two $\mathrm{NbN}$ very thin films grown on an M-plane sapphire substrate.

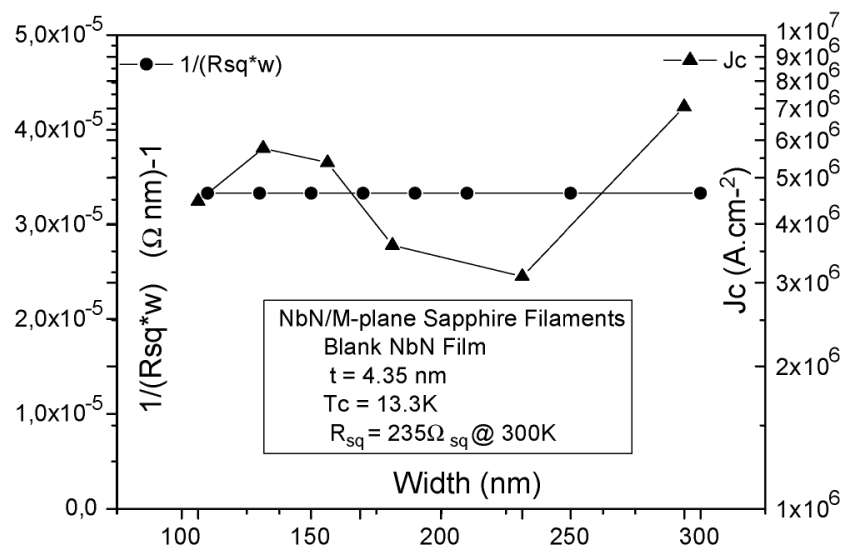

Fig. 7. Measurement of the $\mathrm{NbN}$ filaments conductivity at $300 \mathrm{~K}$ and critical current density at $4.2 \mathrm{~K}$ versus the filament width, after patterning.

on the width of the patterned stripe down to $80 \mathrm{~nm}$, thanks to the e-beam writers used. Tc and square resistance values are also maintained close to those of the un-patterned films grown on M-plane. Critical current density Jc was measured in a 3 to $7 \mathrm{MA} / \mathrm{cm}^{2}$ range at $4.2 \mathrm{~K}$ for the set of samples presented; the apparent variation observed should be due to some measurement imprecisions induced by using the field criteria $\sim 10 \mu \mathrm{V} / \mathrm{cm}$ applied to different geometries.

\section{EPITAXIAL NbN-MgO-NbN JOSEPHSON JUNCTIONS ON R-PLANE SAPPHIRE}

Taking benefit of the high crystalline quality of very thin $\mathrm{NbN}$ layers on sapphire, we used them as a template for growing epitaxial SIS and SNS tri-layers. A $10 \mathrm{~nm}$ base-electrode seed was epitaxially grown at $600^{\circ} \mathrm{C}$ while subsequent deposition took place in the $250-400^{\circ} \mathrm{C}$ range for preventing the nucleation of the HCP phase of $\mathrm{NbN}$. Junctions are patterned using the SNOP process described previously [15].

RF-sputtered MgO ( 1 nm thick) and $\operatorname{Ta}_{X} \mathrm{~N}(\sim 7 \mathrm{~nm}$ thick) barriers are found cubic crystalline and well textured when deposited at about $300^{\circ} \mathrm{C}$. The Current-Voltage characteristics of a $\mathrm{NbN}-\mathrm{MgO}-\mathrm{NbN}$ SIS junction with $50 \mathrm{~nm}$ thick electrodes made on R-plane sapphire is observed in Fig. 8, in the $4 \mathrm{~K}-12 \mathrm{~K}$ range. The gap voltage $\mathrm{V}_{\mathrm{G}}$ and Josephson current are observed up to 12.3 K. Attractive photo-detection properties of such epitaxial thin electrodes junction are under investigation.

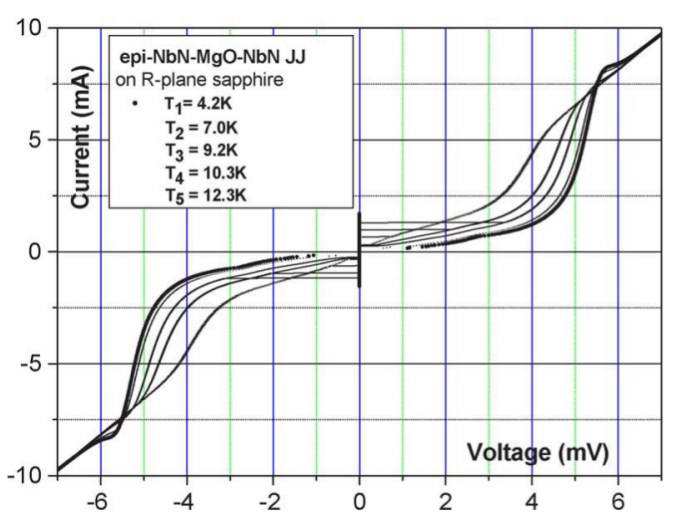

Fig. 8. Current-Voltage characteristics between $4 \mathrm{~K}$ and $12 \mathrm{~K}$ of a $\mathrm{NbN}-\mathrm{MgO}-\mathrm{NbN}$ superconducting tunnel junction with $50 \mathrm{~nm}$ thick $\mathrm{NbN}$ electrodes grown on R-plane sapphire. The gap voltage $\mathrm{V}_{\mathrm{G}}$ observed at $5.3 \mathrm{mV}$ and $4.2 \mathrm{~K}$ decrease down to $3.5 \mathrm{mV}$ at $12.3 \mathrm{~K}$.

\section{CONCLUSION}

Significant progress has been achieved by using the M-plane of sapphire in obtaining higher crystalline quality. Now, the reliability of ultra-thin NbN films and junctions deposited uniformly on 3 and 4 inch diameter sapphire wafers allows us to extend up to 8-inch diameter substrates. We plane further development of superconducting single photon detectors, THz HEB mixers based on $\mathrm{NbN}$ and also devices for low noise quantum analog and digital Josephson circuits.

\section{ACKNOWLEDGMENT}

The authors thank S. Pouget and E. Bellet-Amalric from CEA-INAC SP2M for their support for XRD characterizations and interpretation. They also would like to thank L. Maingault and J-L. Thomassin of CEA-INAC SPSMS for their support at the PTA cleanroom for the e-beam patterning of $\mathrm{NbN}$ nanowires.

\section{REFERENCES}

[1] R. T. Kampwirth and K. E. Gray, IEEE Trans. Mag., vol. 17, pp. $565-568,1981$.

[2] A. I. Braginski and J. Talvacchio, Superconducting Devices, S. T. Ruggiero and D. A. Rudman, Eds. Boston: Academic Press, 1990.

[3] G. N. Gol'tsman, O. Okunev, G. Chulkova, A. Lipatov, A. Semenov, K. Smirnov, B. Voronov, A. Dzardanov, A. Williams, and R. Sobolewski, Appl. Phys. Lett., vol. 79, pp. 705-707, 2001.

[4] A. Divochiy et al., Nature Photonics, vol. 2, no. 5, pp. 302-306, 2008.

[5] E. le Coarer et al., Nature Photonics, vol. 1, no. 8, pp. 473-478, 2007.

[6] J. R. Gao, M. Hajenius, F. D. Tichelaar, T. M. Klapwijk, B. Voronov, E. Grishin, G. N. Gol'tsman, C. A. Zorman, and M. Mehregany, Appl. Phys. Lett., vol. 91, pp. 062504-062506, 2007.

[7] G. L. Kerber, L. A. Abelson, R. N. Elmadjian, and E. G. Ladizinsky, IEEE Trans. Appl. Supercond., vol. 9-2, pp. 3267-3270, 1999.

[8] Z. Wang, A. Kawakami, Y. Uzawa, and B. Komiyama, J. Appl. Phys., vol. 79, pp. 7837-7844, 1996.

[9] A. B. Kaul, S. R. Whiteley, T. Van Duzer, L. Yu, N. Newman, and J. M. Rowell, Appl. Phys. Lett., vol. 78, pp. 99-101, 2001.

[10] J.-C. Villegier et al., IEEE Trans. Appl. Supercond., vol. 11, no. 1, pp. 68-71, 2001.

[11] A. J. Kerman et al., Appl. Phys. Lett., vol. 90, pp. 101110-101112, 2007.

[12] R. Espiau de Lamaëstre, P. Odier, and J.-C. Villegier, Appl. Phys. Lett., vol. 91, pp. 232501-232503, 2007.

[13] R. Espiau de Lamaëstre, P. Odier, E. Bellet-Amalric, P. Cavalier, S. Pouget, and J.-C. Villegier, Journal of Physics: Conference Series, vol. 97, pp. 012046-012052, 2008.

[14] V. L. Noskov et al., Sov. Phys. Crystallogr., vol. 25, no. 4, p. 504, 1980.

[15] R. Setzu, E. Baggetta, and J.-C. Villegier, Journal of Physics: Conference Series, vol. 97, p. 012077, 2008.

[16] L. G. Paratt, Phys. Rev., vol. 95, p. 359, 1954

[17] C. Constancias et al., AVS, vol. 25, no. 6, pp. 2041-2044, 2007.

[18] P. Ruterana et al., , to be published.

[19] C. Jorel et al., , to be published. 